\title{
Alcohol Relapse Induced by Discrete Cues Activates Components of AP-I Transcription Factor and ERK Pathway in the Rat Basolateral and Central Amygdala
}

\author{
Kasia Radwanska', Elzbieta Wrobel ${ }^{2}$, Agnieszka Korkosz ${ }^{2}$, Artur Rogowski ${ }^{2}$, Wojciech Kostowski ${ }^{2}$, \\ Przemyslaw Bienkowski ${ }^{2}$ and Leszek Kaczmarek ${ }^{1, *}$ \\ 'Department of Molecular and Cellular Neuroscience, Nencki Institute of Experimental Biology, Warsaw, Poland; '2 Department of Pharmacology, \\ Institute of Psychiatry and Neurology, Warsaw, Poland
}

\begin{abstract}
Alcohol-related cues may induce relapse to heavy alcohol drinking and promote molecular adaptations in discrete brain regions. An exact nature of these molecular alterations is still unknown. In the present study, rats trained to self-administer ethanol were tested for cueinduced reinstatement of ethanol seeking after 30 days of abstinence. Next, a detailed immunocytochemical analysis of c-Fos activation was performed within seven nuclei of the amygdala. In the second experiment, c-Fos activation after reinstatement of ethanol seeking induced by discrete cues was compared with the activation pattern of its putative partner (c-Jun) and regulators (extracellular signalregulated kinases and c-Jun N-terminal kinases). Reexposure to ethanol-associated context cues (an extinction session) potentiated c-Fos expression within the basolateral and central amygdala. Repeated presentation of ethanol-associated discrete cues in an extinction/ reinstatement session led to even stronger c-Fos activation in the latter nuclei. In the second experiment, reexposure to the ethanolassociated context and discrete cues activated both c-Jun and extracellular signal-regulated kinases (ERKI/2) in the basolateral amygdala. Our observations suggest that the basolateral and central amygdala may be specifically involved in alcohol-seeking behavior induced by discrete cues.

Neuropsychopharmacology (2008) 33, I835-1846; doi: 10.1038/sj.npp. I30 I567; published online 12 September 2007
\end{abstract}

Keywords: alcohol self-administration; alcohol seeking; reinstatement; c-Fos; P-c-Jun; c-Jun N-terminal kinase

\section{INTRODUCTION}

Relapse to heavy alcohol drinking, even after long periods of abstinence, is a major problem in the treatment of alcohol addiction. Many studies have indicated that passive exposure to alcohol- or drug-associated environmental cues may elicit alcohol/drug-seeking behavior in human addicts after weeks or months of abstinence (Drummond et al, 1990; George et al, 2001). In line with clinical data, ethanol is a strong reinforcer for laboratory animals (Samson et al, 2000), and alcohol-associated cues elicit drug-seeking behavior in animals trained to self-administer alcohol, even after protracted abstinence (Shalev et al, 2002; Wedzony et al, 2003; Bienkowski et al, 2004). It has been postulated that both gene expression and protein synthesis are responsible for the persistent nature of addiction and the occurrence of relapse (Tran-Nguyen et al, 1998; Berke and Hyman, 2000; Shaham et al, 2000). Thus, the identification

*Correspondence: Dr L Kaczmarek, Laboratory of Molecular Neurobiology, Nencki Institute, Pasteura 3 St, 02-093 Warsaw, Poland, Tel: + 482265930 0I, Fax: + 482282253 42,

E-mail: leszek@nencki.gov.pl

Received 10 April 2007; revised 10 August 2007; accepted II August 2007 of brain circuits and molecular processes associated with cue-induced relapse to drug-seeking behavior seems to be crucial for understanding addiction processes (Asan, 1998; Shaham et al, 2003).

There are multiple transcription factors which can be activated in the brain by drugs of abuse or drug-related stimuli, but only a few, including the AP-1 complex, have been shown to be involved in addiction. The AP-1 transcription factor is a complex of Fos and Jun proteins, known to regulate the broad spectrum of neuronal plasticity-related genes (Kaczmarek, 1993; Rylski and Kaczmarek, 2004). It has been shown that c-Fos expression is induced in the amygdala after reexposure to drug-related stimuli (Brown et al, 1992; Neisewander et al, 2000; Ciccocioppo et al, 2001). The upstream regulators of this event are mostly unknown although possible candidates are extracellular signal-regulated kinases (ERK) which have been found to control $c$-fos expression in many experimental paradigms (Sgambato et al, 1998; Radwanska et al, 2005). Furthermore, ERKs have been shown to be activated in the central amygdala (CeA) after cue-induced relapse to cocaine seeking and inhibition of ERKs in the CeA decreased cocaine seeking after drug withdrawal (Lu et al, 2005). All these observations suggest that molecular alterations in the 
amygdala may be involved in cue-induced relapse to drug seeking (Grimm and See, 2000; Yun and Fields, 2003). However, the activation of transcription factors and signaling cascades in the amygdala has never been analyzed in detail in animal models of relapse to alcohol seeking. Furthermore, the careful molecular dissection of multiple nuclei of the amygdala has never been performed in the context of cueinduced relapse to alcohol seeking in animals trained to self-administer ethanol solution.

A better understanding of environmental factors (eg discrete or context alcohol-associated cues) that contribute to alcohol relapse, as well as molecular basis of this phenomenon, would be of substantial clinical benefit. Given the above, the purpose of the present study was to investigate the molecular correlates of alcohol relapse induced by discrete cues in rats trained to lever press for ethanol. In the first experiment, we examined the pattern of c-Fos protein activation within seven nuclei of the amygdala after reexposure to alcohol-associated context or context + discrete cues following 30 day of abstinence. This time point was selected on the basis of our previous finding that alcohol seeking increased with time and was more intense after 30 days than after 24-h withdrawal (Bienkowski et al, 2004).

The second part of the study was designed to confirm that the observed c-Fos expression in specific amygdaloid nuclei (which was the strongest in the group exposed to the context and discrete cues) could be functional, ie might lead to AP-1 complex formation and subsequent changes in gene expression. For this aim, we analyzed the activation pattern of c-Jun, as well as ERKs (ERK1 and 2) and c-Jun Nterminal kinases (JNK1 and 2), ie protein kinases known to regulate the expression of $c$-fos and phosphorylation of c-Jun, respectively (Gupta et al, 1996; Sgambato et al, 1998).

\section{MATERIALS AND METHODS}

\section{Subjects}

Male Wistar rats weighing 330-360 g at the beginning of the study were housed 2 per standard plastic cage in a room with controlled environmental conditions: temperature of
$22 \pm 1^{\circ} \mathrm{C}, \sim 60 \%$ humidity and a $12 \mathrm{~h}: 12 \mathrm{~h}$ light-dark cycle (lights on at $6 \mathrm{am}$ ). The animals were supplied by a breeder (Medical Research Center, Polish Academy of Sciences, Warsaw, Poland) 14 days before the start of behavioral procedures. Unless otherwise stated, standard laboratory chow (Labofeed H, WPiK, Kcynia, Poland) and tap water was available ad libitum. Rats were handled for $1 \mathrm{~min}$ and were weighed at least twice a week before and after the start of behavioral procedures.

All procedures used in the present study were in full accordance with the ethical standards laid down in respective European (directive no. 86/609/EEC) and Polish regulations. All efforts were made to minimize animal suffering and to reduce the number of animals used.

\section{Drugs}

Ethanol solutions were prepared daily from a $96 \%$ stock solution (Rectified Spirit; Polmos, Zielona Gora, Poland) and tap water. Unless stated otherwise, all chemicals for immunocytochemistry were purchased from Sigma-Aldrich (St Louis, MI, USA).

\section{Self-Administration Apparatus}

Some rats (see Table 1) were trained to respond for ethanol. Lever pressing for ethanol was studied in eight identical chambers (Coulbourn Inc., Allentown, PA, USA). The chambers consisted of stainless-steel test cages (E10-10TC, Coulbourn; Skinner boxes) enclosed within sound-attenuating cubicles with fans for ventilation and background white noise (for details, see Bienkowski et al, 1999; Bienkowski et al, 2004). A white house light was centered near the top of the front wall of the cage. The start of each session was signaled by turning the house light on. The cage was also equipped with two response levers separated by the liquid delivery system (the liquid dipper; E14-05, Coulbourn). The liquid dipper and the response levers were mounted on the front wall of the cage, $4 \mathrm{~cm}$ above a stainless-steel grid floor. It was assumed that the interior space of the cage provided a set of context cues associated with alcohol self-administration.

Table I Experimental Groups and Their Behavioral History

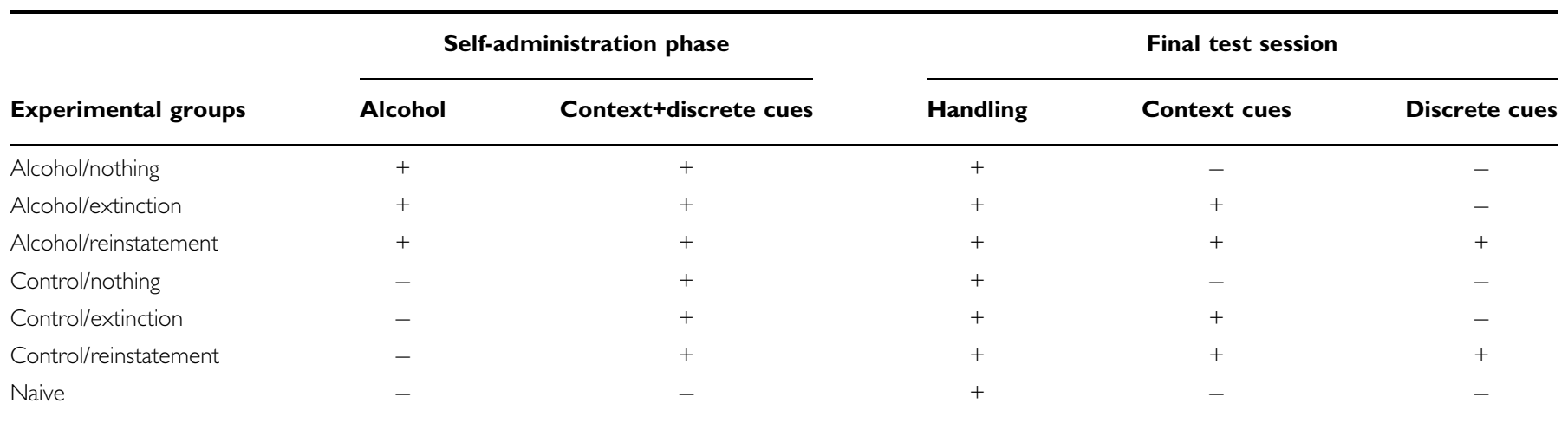

Experimental animals were divided into seven groups ( $n=3-6$ rats) with different history of self-administration and reinstatement. During the self-administration

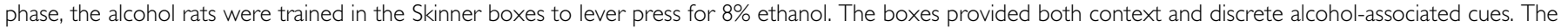

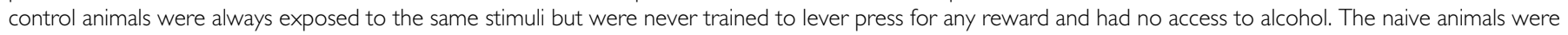
always kept in their home cages and were only occasionally handled. During the final test session, the animals were exposed either to short handling ('nothing'), handling and the Skinner boxes ('extinction') or handling and alcohol-associated discrete cues in the Skinner boxes ('reinstatement'; see Figure I a for other details). 
Only one lever (the active lever) activated the liquid dipper. Presses on the other lever (the inactive lever) were recorded but had no programmed consequence. The location of the active lever (left or right) was randomized across all the alcohol subjects. The liquid dipper presented alcohol solution in a volume of $0.1 \mathrm{ml}$ for $5 \mathrm{~s}$ and provided a set of discrete alcohol-associated cues, ie a brief audible click and white stimulus light $(4 \mathrm{~W})$ located inside the liquid dipper hole. The stimulus light was on during the entire 5-s dipper activation. After that time, the liquid dipper and its stimulus light was switched off. Programming of every experimental session as well as data recording was made using the L2T2 Software package (Coulbourn) running on an IBM-compatible PC.

\section{Behavioral Procedure}

The rats were trained according to the procedure described by Bienkowski et al (2004). This procedure consisted of four phases: initiation, alcohol self-administration, abstinence and reinstatement (see Figure 1a).

Initiation and maintenance of ethanol self-administration. Rats were trained to respond for an ethanol solution according to the sucrose-fading procedure (Samson, 1986; Bienkowski et al, 1999). All self-administration sessions lasted $30 \mathrm{~min}$ and one session was given each day between 2 and 5 p.m. At the beginning of the initiation phase, the rats were deprived of water for $22 \mathrm{~h}$ /day and shaped to lever press for $8 \%(\mathrm{w} / \mathrm{v})$ sucrose solution on the FR1 schedule of reinforcement. As soon as lever pressing was established, ie after 1-4 days of training, water started to be freely available in the home cages. Starting on day 5 of training, the alcohol group received $2 \%(\mathrm{w} / \mathrm{v})$ alcohol- $8 \%(\mathrm{w} / \mathrm{v})$ sucrose. Then, over the next 8-10 sessions alcohol concentrations were gradually increased from 2 to $8 \%$ and sucrose concentrations were decreased from 8 to $0 \%$. Rats from the alcohol group were allowed to stabilize their $8 \%$ alcohol consumption in a self-administration phase which lasted 30 days.

The control rats (Table 1) were deprived of water according to the identical schedule as the alcohol group but were never trained to lever press for any solution. The control group was introduced to control for the effect of non-specific stimulation with the context and discrete cues. Each control rat was paired ('yoked') with one alcohol rat. The control rats received the same handling and stimulation but never received any ethanol solution. The liquid delivery system in the control rat's cage was activated each time the respective rat from the alcohol group pressed the active lever and gained access to ethanol. The liquid dippers in the control cages presented the same discrete stimuli but were always filled with tap water. Responses emitted by the control rats were recorded but had no programmed consequences. In addition, we used a group of naive rats which were exposed to handling only. These rats stayed in their home cages during the whole experiment and were occasionally handled ( 1 min twice a week) (see Table 1 for the experimental groups and Figure 1a for the experimental procedure).

Abstinence period. After the 30-day self-administration phase, all animals were subjected to 30 days of forced abstinence. During the abstinence phase, the animals stayed in their home cages and did not receive any training but were handled for 1 min twice a week. During the last week of abstinence, the rats were handled daily for $1 \mathrm{~min}$ and received an i.p. injection of saline $(0.5 \mathrm{ml})$ to habituate them to this procedure before the final anesthesia with an i.p. injection of chloral hydrate.

Final test session after 30 days of imposed abstinence. On the final test day, the alcohol and control rats were randomly assigned to one of three experimental groups: nothing, extinction or reinstatement (see Figure 1a and Table 1). The nothing group was briefly handled $(1 \mathrm{~min})$ and anesthetized 30 or $90 \mathrm{~min}$ later. The rats from the extinction group (ie alcohol/extinction and control/extinction rats) were exposed for $30 \mathrm{~min}$ to the Skinner boxes where they had previously been trained during the self-administration phase. Lever pressing had no consequences and thus the extinction group received no alcohol and was not exposed to the discrete cues. The animals were anesthetized 30 or $90 \mathrm{~min}$ after the start of the extinction session.

The reinstatement group went through the extinction/ reinstatement procedure (Bienkowski et al, 1999, 2000). The animals were exposed for $30 \mathrm{~min}$ to the Skinner boxes where they had previously been trained during the self-administration phase. During the first $20 \mathrm{~min}$, the liquid delivery system was off and the animals received neither alcohol nor were exposed to the discrete cues (an extinction phase). For the last $10 \mathrm{~min}$ of the session (a reinstatement phase), the alcohol-associated discrete cues were repeatedly delivered $(15 \times 7.5 \mathrm{~s})$ according to a random time (RT) $15 \mathrm{~s}$ schedule. The stimulus complex included the audible click and the white light illuminated inside the liquid dipper hole. During the reinstatement phase, the dipper cup was filled with water. The animals were anesthetized 30 or 90 min after the start of the final test session.

Seven experimental groups were used in the first experiment: the alcohol/nothing $(n=3)$, alcohol/extinction $(n=5), \quad$ alcohol/reinstatement $(n=6)$, control/nothing $(n=3)$, control/extinction $(n=4)$, control/reinstatement $(n=6)$, and naive group $(n=6)$, ie rats with no training experience (see Table 1). The alcohol/nothing and control/ nothing group showed marginal c-Fos expression and this finding confirmed our previous observations (Wedzony et al, 2003). Given the above, the two groups were pooled. The nothing animals and extinction animals were not included in the second experiment (in which the possible partners and regulators of c-Fos were analyzed).

\section{Immunocytochemistry}

Immunocytochemical procedures were based on those described previously by Radwanska et al (2005). All animals were anesthetized $(350 \mathrm{mg} / \mathrm{kg}$ of chloral hydrate, i.p.) 30 or $90 \mathrm{~min}$ from the onset of the final test session and perfused for $1 \mathrm{~min}$ with ice-cold saline with $0.05 \% \mathrm{NaF}$ followed by $4 \%$ paraformaldehyde (PFA) in $0.1 \mathrm{M}$ phosphate-buffered saline (PBS; $\mathrm{pH} 7.4$ ) for $15 \mathrm{~min}$. Brains were removed from the skull and post-fixed in the $4 \%$ PFA solution for $24 \mathrm{~h}$ at $4{ }^{\circ} \mathrm{C}$. The brains were frozen on dry-ice and stored at $-70^{\circ} \mathrm{C}$ until further processing. Coronal brain sections $(30 \mu \mathrm{m})$ were cut with a cryostat (Leica, Nussloch, Germany) at 


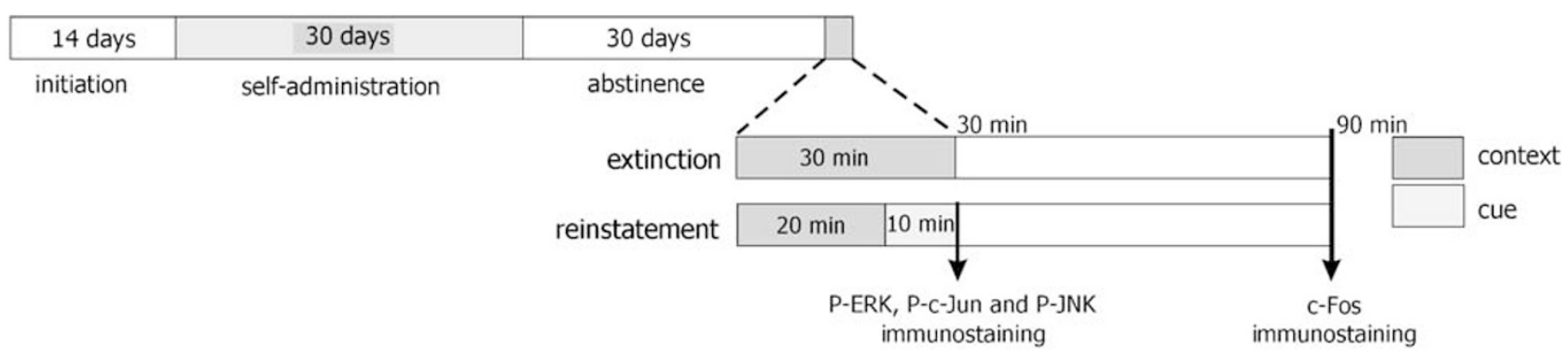

b self-
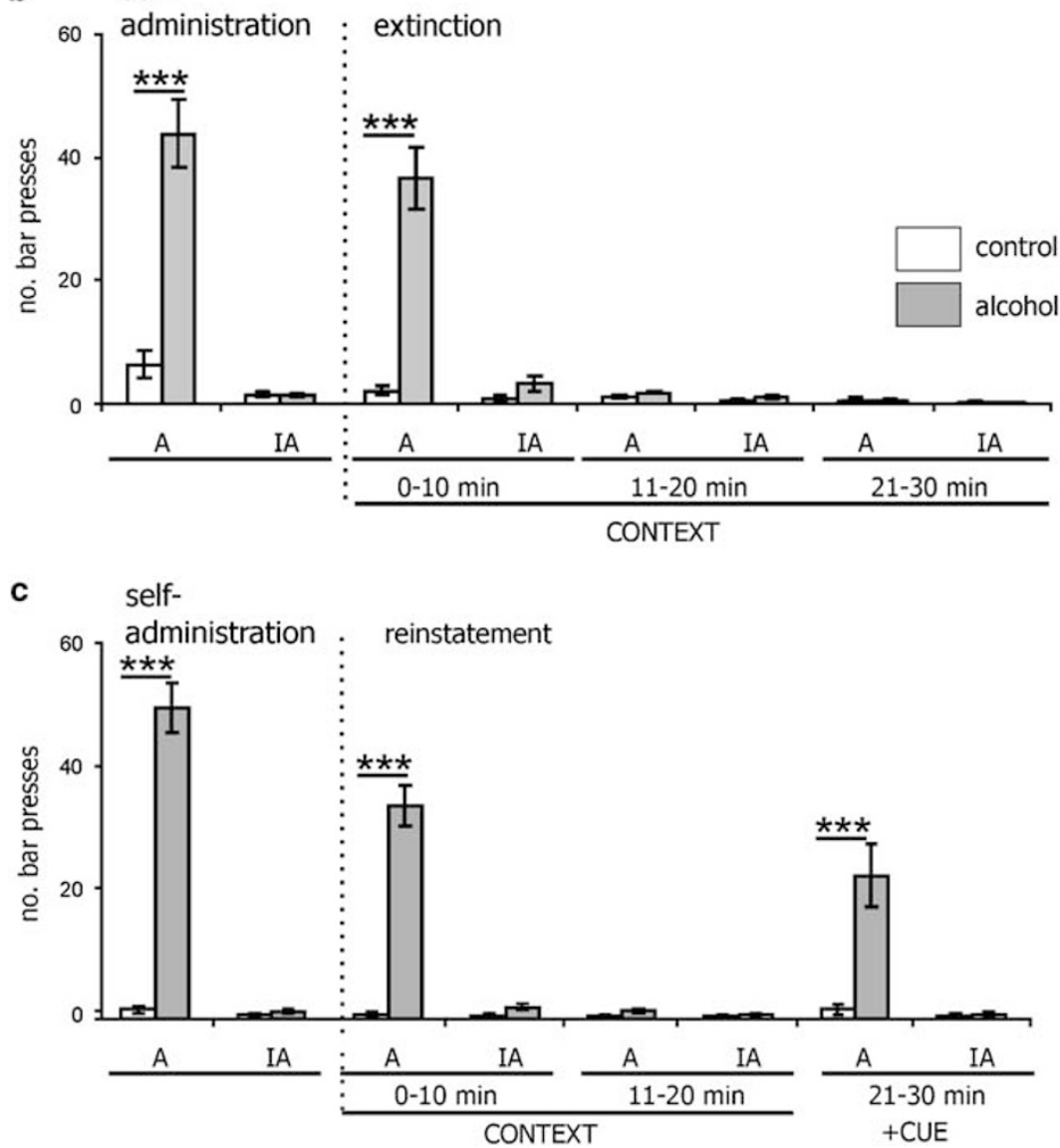

Figure I General design of the study (a) and alcohol-seeking behavior during the final test session (b, c). (a) The experimental procedure consisted of the initiation phase, self-administration and abstinence periods, and ended with the final test session. During the final session, the animals were reexposed to the alcohol self-administration context ('context', the extinction group) or context and discrete cues ('cue') according to the within-session extinction/ reinstatement paradigm (the reinstatement group). No alcohol was available during the final session. The animals were anesthetized and perfused 30 (for P-extracellular signal-regulated kinases (ERK), P-c-Jun, and P-JNK immunostaining) or 90 min (for c-Fos immunostaining) from the beginning of the final test session. $\downarrow$ indicates anesthesia. For other details, see Materials and Methods and Table I. (b) Mean ( \pm SEM) number of non-reinforced responses on the active ('A') and inactive ('IA') lever during the last week of alcohol self-administration and during the final test session (the extinction session) is shown for the alcohol and control rats from the extinction group. The alcohol rats were trained to press the active lever for $8 \%$ ethanol and were reexposed to the alcohol self-administration context after 30-day abstinence. During the final session, alcohol was not available. The control animals were always exposed to the same stimuli but were never trained to lever press for any reward and had no access to alcohol. A: active lever (the alcohol rats received portion of alcohol during self-administration phase if pressed that lever). IA: inactive lever (pressing that lever had no programmed consequences). Note that non-reinforced responding on the previously active lever was limited to the alcohol/extinction rats (Table I). Data were analyzed with a mixed factor ANOVA with repeated measures on time (for the alcohol animals: effect of time: $F(2,36)=54.23, p<0.00$ I; effect of lever: $F(I, I 8)=38.27$, $p<0.00$ I); for the control animals: effect of time: $F(2,28)=10.03, p<0.05$; effect of lever: $F(I, \mid 4)=1.28, p>0.05$ ); ***** $p<0.00$ I alcohol vs control, Tukey's test. (c) Mean ( \pm SEM) number of non-reinforced responses on the active (' $A$ ') and inactive ('I $A$ ') lever during the last week of alcohol self-administration and during the final test session (the extinction/reinstatement session) is shown for the alcohol and control rats from the reinstatement group. The alcohol rats were trained to press the active lever for $8 \%$ ethanol and were reexposed to the alcohol self-administration context and discrete cues after 30-day abstinence. During the final session, alcohol was not available. The control animals were always exposed to the same stimuli but were never trained to lever press for any reward and had no access to alcohol. During the final test session, the animals were exposed for $30 \mathrm{~min}$ to the self-administration context. The alcohol-paired discrete cues were repeatedly presented in the last $10 \mathrm{~min}$ of the session. Note that non-reinforced responding on the previously active lever was limited to the alcohol/reinstatement rats (Table I). Data were analyzed with a mixed factor ANOVA with repeated measures on time (for the alcohol animals: effect of time: $F(2,44)=24.57, p<0.001$; effect of lever: $F(1,22)=149.99$, $p<0.00$ I; for the control animals: effect of time: $F(2,44)=1.71$, $p>0.05$; effect of lever: $\mathrm{F}(\mathrm{I}, 22)=0.90, p>0.05)$. **** $p<0.00 \mathrm{I}$ alcohol vs control, Tukey's test. 
$-24^{\circ} \mathrm{C}$ and kept in PBS with $0.05 \% \mathrm{Na}_{3} \mathrm{~N}$ and $0.05 \% \mathrm{NaF}$ at $4{ }^{\circ} \mathrm{C}$. For immunocytochemistry, the sections were washed 3 times for $6 \mathrm{~min}$ in Tris-buffered saline (TBS; $0.05 \mathrm{M}$ Tris, $0.9 \% \mathrm{NaCl}, \mathrm{pH} 8.0$ ). Endogenous peroxidase activity was quenched by washing in $10 \%$ methanol/1\% $\mathrm{H}_{2} \mathrm{O}_{2}$ in TBS. The cell membrane was permeabilized with $0.2 \%$ Triton $\mathrm{X}-100$ in TBS for $15 \mathrm{~min}$. After three washes for $6 \mathrm{~min}$ in TBS, the sections were incubated with the selective antibodies directed against c-Fos (sc-52; Santa Cruz Biotechnology, Santa Cruz, CA, USA), phospho-c-Jun (P-c-Jun; \#9621; Cell Signaling, Technology, Beverly, MA, USA), phospho-ERK1/2 (P-ERK1/2; \#9102; Cell Signaling, Technology, Beverly, MA, USA), or phospho-JNK (P-JNK1/2; \#9251; Cell Signaling, Technology). The dilutions and incubation conditions varied according to the primary antibody: c-Fos $(1: 500)$ - overnight at $4^{\circ} \mathrm{C}$ in TBS, P-c-Jun $(1: 100)$-overnight at $4{ }^{\circ} \mathrm{C}$ in TBS with $0.5 \%$ Triton $\mathrm{X}-100$, P-ERK1/2 $(1: 400)$ - overnight at $4{ }^{\circ} \mathrm{C}$ in TBS with $0.05 \%$ $\mathrm{NaF}$, and P-JNK1/2 (1:100)-overnight at $4^{\circ} \mathrm{C}$ in TBS with $0.05 \% \mathrm{NaF}$. Activation of c-Jun was evaluated with the antibody selectively recognizing c-Jun protein phosphorylated at Ser73. The activation pattern of ERK1 and ERK2 was assessed with the antibody recognizing ERKs only when phosphorylated on the activator loop (Thr183/Tyr185) (Impey et al, 1999). The activation pattern of JNK1 and JNK2 was assessed with the antibody recognizing JNKs only when activated, ie phosphorylated, at Thr183/Tyr185 (Impey et al, 1999). After the incubation with the primary antibody, the sections were washed 3 times for 6 min in TBS and incubated with the secondary antibody $(1: 250$, biotynylated anti-IgG antibody; Vector Laboratories, Burlingame, CA, USA) for $2 \mathrm{~h}$ at room temperature. After incubation with the secondary antibody, the sections were washed 3 times for 6 min in TBS and incubated with avidinbiotin horseradish peroxidase complex $(1: 500$ in TBS; Vector Laboratories, Burlingame, CA, USA) for $1 \mathrm{~h}$. The sections were washed 3 times for $6 \mathrm{~min}$ in TBS $(0.25 \mathrm{M}$ Tris; $\mathrm{pH}$ 7.5) and finally developed with $1 \mathrm{mg} / \mathrm{ml}$ diaminobenzidine $/ 0.005 \% \mathrm{H}_{2} \mathrm{O}_{2}$ in TBS for $30 \mathrm{~min}$. The sections were washed 3 times in TBS to stop the reaction. The sections were mounted on poly-lysine-covered slides (Sigma-Aldrich, St Louis, MI, USA), air-dried, dehydrated in ethanol solutions and xylene, and embedded in Entellan (Merck, Darmstadt, Germany).

For each analyzed protein two runs of staining were performed. In each run, we included sections from the naive group and either the extinction or reinstatement groups. Photomicrograph of stained brain sections were taken with an Olympus DP50 digital camera (Olympus Optical Polska Sp. z o.o., Warsaw, Poland). The pictures were digitally sharpened before the analysis with Adobe ${ }^{\circledR}$ Photoshop ${ }^{\circledR}$ software. The degree of sharpening was the same for all pictures. The number of c-Fos, phospho-c-Jun (P-c-Jun), phospho-ERK1/2 (P-ERK1/2), and phospho-JNK1/2 (PJNK1/2) stained nuclei was counted for the seven regions of interest, namely: the ventral and dorsal tips of lateral nucleus ( $\mathrm{LaV}$ and $\mathrm{LaD}$ ), basolateral (BLA), posterior part of basomedial (BMP), capsular, and lateral partitions of the central nucleus $(\mathrm{CeC} / \mathrm{L})$, medial partition of the central nucleus (CeM), and posterodorsal part of medial (MePD) nucleus of amygdala with ImageJ software (NIH). The area of each region was measured on the picture and expressed in square inches. The density of the immuno-stained nuclei was counted according to the formula: the number of immuno-stained nuclei within the analyzed region/the area of the analyzed region (the whole structure of interest on the section) and expressed as arbitrary units of density. The number of the stained nuclei was automatically counted with the 'Threshold' function of the ImageJ software, which marks all pixels of chosen gray value and counts all groups of marked pixels (stained nuclei) within the selected area. To control the differences between the staining runs the number of immunopositive nuclei in the piriform cortex of the naive group was compared between the two runs of the staining (in this brain region c-Fos expression is relatively high even in naive animals). In general, we did not found significant differences between the naive groups in two staining runs and thus we did not recalculate the data for the other experimental groups to adjust to the hypothetical error of a staining run. Due to differences in staining intensity between different immunostainings (especially between P-c-Jun and P-ERK immunostaining), the values of the thresholded pixels were subjectively optimized separately for each immunostaining reaction to include all the visible nuclei. Therefore, it was not possible to compare the density of stained nuclei between the different immunostaining reactions (eg c-Fos within $\mathrm{LaV}$ vs P-ERK within $\mathrm{LaV}$ ).

Two to three sections per animal and per immunostaining reaction were taken from the brain region posterior to Bregma (around $-2.56,-2.80$, and $-3.04 \mathrm{~mm}$ ). The position of the amygdaloid complex was determined according to the atlas of the rat brain (Paxinos and Watson, 1998) (Figure 2a).

\section{Statistics}

A mixed factor analysis of variance (ANOVA) with repeated measures on time followed by post hoc Tukey's test was used to analyze the animals' behavior (presses on the active and inactive lever).

Mean bilateral densities of stained nuclei from the regions of interest were analyzed. Two to three brain sections per animal per analyzed brain structures were used. A KruskalWallis ANOVA was performed to analyze the effect of experimental treatments on c-Fos expression within the amygdaloid nuclei. All experimental groups except for the nothing and naive group were included in this analysis. Mann-Whitney $U$-test with the sequential Bonferroni corrections for $p$-values (Quinn and Keough, 2002) was chosen for pair-wise comparisons of the groups. Spearman's $R$-test was employed to search for correlations between $\mathrm{c}$ Fos expression and alcohol seeking in the final test session (for the alcohol groups). Lever pressing of the animals from the alcohol groups during the extinction or extinction/ reinstatement session was analyzed in 10-min-blocks (see Figure $1 \mathrm{a}-\mathrm{c})$. A probability level $(p)$ less than 0.05 was considered significant. STATISTICA software package (StatSoft, Krakow, Poland) was used to analyze all data.

\section{RESULTS}

\section{Behavioral Parameters}

Rats were trained to self-administer $8 \%$ ethanol for 1 month (see Table 1 and Figure 1a for details). Numbers of presses 
averaged across the last week of the alcohol self-administration phase for the alcohol rats ranged from 43.2 to 100.0 presses per $30 \mathrm{~min}$. In the same group, alcohol intakes ranged from 0.62 to $1.19 \mathrm{~g} / \mathrm{kg}$ per $30 \mathrm{~min}$. Numbers of presses on the inactive lever averaged across the last week of the self-administration phase ranged from 0.0 to 5.0 presses per $30 \mathrm{~min}$. The control rats received no alcohol but were exposed to the same context and discrete cues as the alcohol animals. The control rats did not show any specific operant behavior (Figure $1 \mathrm{~b}$ and $\mathrm{c}$ ).

After 30 days of abstinence, reexposure of the alcohol rats to the self-administration context was associated with vigorous non-reinforced responding on the previously active lever (Figure $1 \mathrm{~b}$ and $\mathrm{c}$ ). These responses were observed mainly during the first $10 \mathrm{~min}$ of the final session. A total of 15 presentations of the discrete alcohol-paired stimulus complex (the reinstatement phase) reinstated responding on the active lever in the alcohol/reinstatement group (Figure 1c). In all groups, responding on the inactive lever was marginal. As expected, the control groups did not show any consistent operant behavior and did not prefer the active lever.

\section{Immunocytochemistry}

c-Fos expression. In the first experiment, we analyzed c-Fos expression within the seven nuclei of the amygdala after reexposure to the ethanol-associated context or context and discrete cues (Table 1). c-Fos protein expression was evaluated $90 \mathrm{~min}$ from the onset of the extinction or extinction/reinstatement session. This time point was chosen as it corresponds to maximal expression of c-Fos protein (Herdegen and Leah, 1998).
The densities of c-Fos immunopositive nuclei in the analyzed regions of the amygdala are shown in Table 2. Almost no c-Fos immunopositive nuclei were found in the amygdala of the naive rats (Table 2 and Figure 2c). The same was true for the nothing rats, ie the alcohol and control animals which were killed after 30 days of abstinence without being exposed to the Skinner boxes (Table 2). The naive and nothing rats did not differ in term of c-Fos expression (all $p$-values $>0.05$ ).

In the other experimental groups, which were reexposed to the Skinner boxes, c-Fos was activated within the $\mathrm{LaV}$ (the Kruskal-Wallis ANOVA: $H(3)=12.22, p<0.05$ ), BLA $(H(3)=13.10, p<0.05)$, and $\mathrm{CeC} / \mathrm{L}(H(3)=10.84, p<0.05)$. c-Fos expression was increased in the alcohol/extinction group as compared to the control/extinction group in the $\mathrm{LaV}(p<0.05)$ and BLA $(p<0.05)$. c-Fos expression in the alcohol/reinstatement group differed from that found in the control/reinstatement group within the $\mathrm{LaV}(p<0.05)$, BLA $(p<0.01)$, and $\mathrm{CeC} / \mathrm{L}(p<0.05)$.

In comparison to the alcohol/extinction group, the reinstatement phase in the alcohol/reinstatement group increased c-Fos expression in the BLA $(p<0.05)$ and $\mathrm{CeC} / \mathrm{L}$ $(p<0.05)$ (Table 2). In agreement with $c$-Fos function as a transcription factor component, c-Fos immunostaining showed specific nuclear localization (Figure $2 b$ ).

Next, we tested the hypothesis that the distribution of c-Fos depends on the performance of operant behavior. In general, c-Fos expression did not correlate with alcohol-seeking behavior (active lever pressing) during the final test session in any of the analyzed nuclei. c-Fos expression in the CeM correlated with lever pressing of the alcohol rats during the second phase (11-20 min, Figure 1c) of the final session $(p<0.01)$.

Table 2 c-Fos Expression in the Rat Amygdala Following Reexposure to Alcohol-Paired Stimuli

Experimental groups

\begin{tabular}{|c|c|c|c|c|c|c|}
\hline \multirow[b]{2}{*}{ Nucleus } & \multirow[b]{2}{*}{ Naive $(n=6)$} & Nothing & \multicolumn{2}{|c|}{ Extinction } & \multicolumn{2}{|c|}{ Reinstatement } \\
\hline & & Control+alcohol $^{\mathrm{a}}(n=6)$ & Control $(n=4)$ & Alcohol $(n=5)$ & Control $(n=6)$ & Alcohol $(n=6)$ \\
\hline $\mathrm{LaV}^{\$}$ & $4.2 \pm 0.1$ & $7.5 \pm 4.2$ & $7.9 \pm 1.2$ & $16.8 \pm 1.4^{*}$ & $12.5 \pm 4.4$ & $28.0 \pm 3.6 *$ \\
\hline$B L A^{\$}$ & $1.4 \pm 0.9$ & $5.0 \pm 4.0$ & $7.0 \pm 1.3$ & $16.4 \pm 3.4 *$ & $9.6 \pm 3.7$ & $37.7 \pm 6.1 * * *, 8$ \\
\hline $\mathrm{CeC} / \mathrm{L}^{\$}$ & $0.2 \pm 0.2$ & $5.7 \pm 3.5$ & $4.4 \pm 0.7$ & $3.9 \pm 3.6$ & $2.2 \pm 1.0$ & $16.3 \pm 6.4^{*}, 8$ \\
\hline MePD & $0.6 \pm 0.3$ & $0.6 \pm 0.6$ & $15.4 \pm 3.3$ & $15.5 \pm 3.8$ & $20.9 \pm 3.9$ & $33.2 \pm 3.5$ \\
\hline
\end{tabular}

Abbreviations: BLA, basolateral amygdaloid nucleus; BMP, basomedial amygdaloid nucleus, posterior part; CeC/L, central amygdaloid nucleus, lateral part, and capsular division; CeM, central amygdaloid nucleus, medial division; LaD, lateral amygdaloid nucleus, dorsal part; LaV, lateral amygdaloid nucleus, ventral part; MePD, posterodorsal part of the medial amygdaloid nucleus

The alcohol rats were trained to lever-press for $8 \%$ ethanol. The control animals were always exposed to the same stimuli but were never trained to lever press for any reward and had no access to alcohol. The naive animals were always kept in their home cages and were only occasionally handled. During the final test session, the animals were exposed either to the alcohol self-administration context ('extinction') or context and alcohol-associated discrete cues ('reinstatement'). The rats were anesthetized and perfused 90 mins from the beginning of the final session. The nothing rats were anesthetized 90 mins after a brief handling. The immunocytochemistry staining with c-Fos antibody was performed on 30- $\mu \mathrm{m}$ coronal brain sections. Mean density of c-Fos positive nuclei ( \pm SEM) was counted within the nuclei of the amygdala. Kruskal-Wallis ANOVA $\left({ }^{\$} p<0.05\right)$ was performed followed by Mann-Whitney U-test with Bonferroni corrections for $p$ values $(* p<0.05$, *** $p<0.01$ alcohol vs control, ${ }_{p} p<0.01$ alcohol/extinction vs alcohol/reinstatement). The nothing and naive group was not included in the statistical analyses but shown in the table to demonstrate the basal level of c-Fos expression; LaD, LaV, BLA, BMP, CeM, CeC/L, MePD.

aThe control/nothing $(n=3)$ and alcohol/nothing rats $(n=3)$ were pooled. 
a

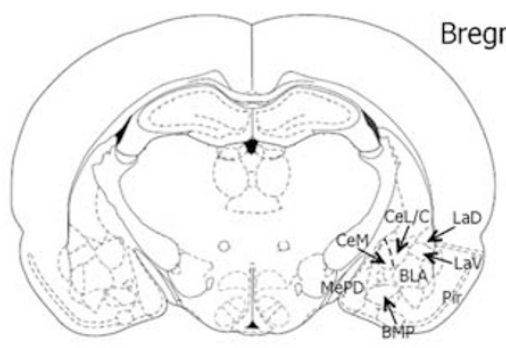

b

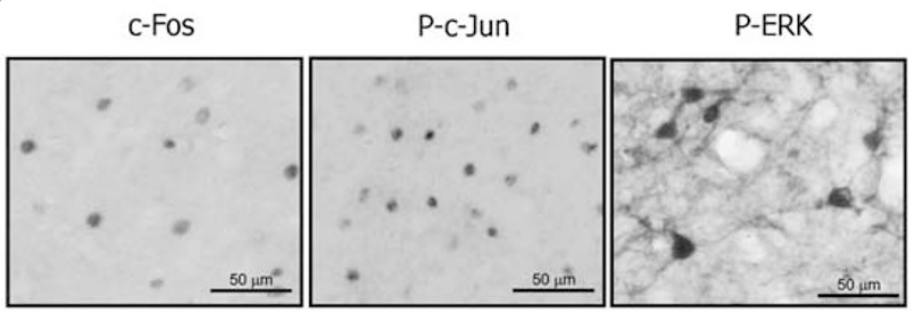

C

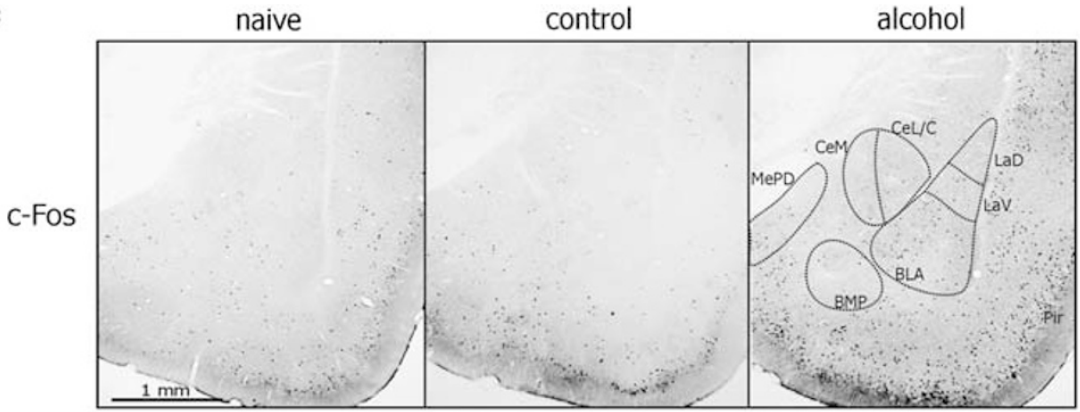

d

P-C-Jun

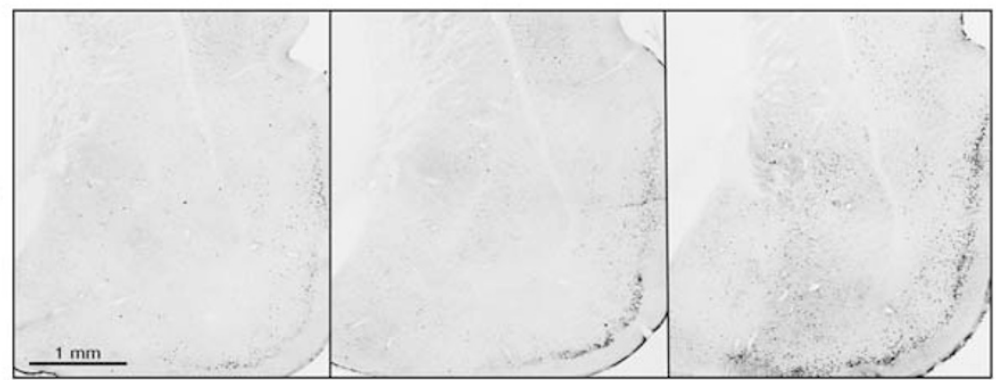

e

P-ERK

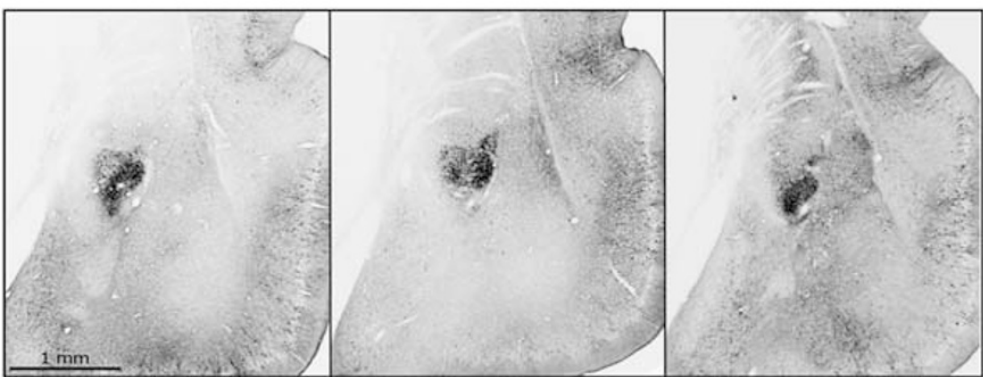

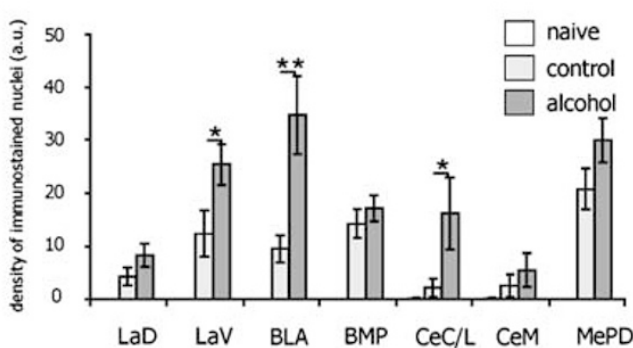
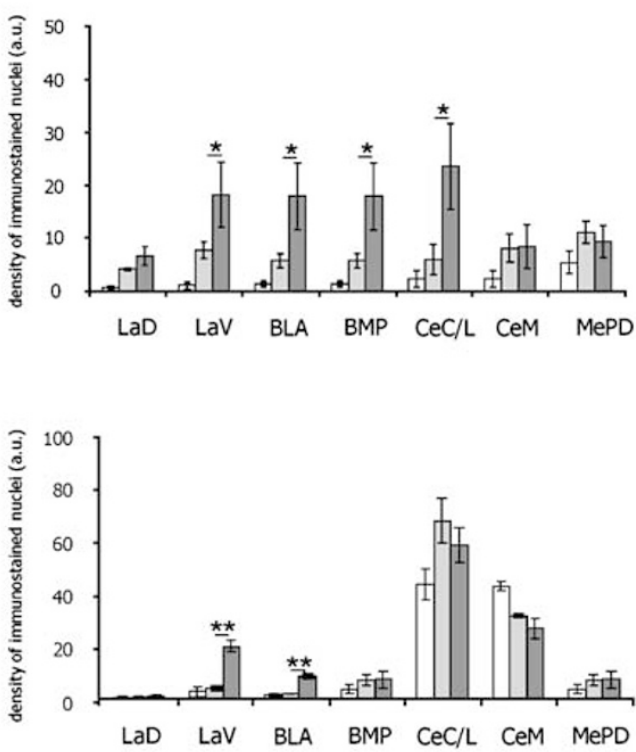

Figure 2 Results of the second experiment in which possible partners and regulators of c-Fos were analyzed. The extinction/reinstatement session led to c-Fos, P-c-Jun, and P-extracellular signal-regulated kinases (ERK) I/2 expression in the amygdaloid nuclei. The alcohol rats were trained to lever press for $8 \%$ ethanol and exposed to the ethanol-related stimuli after 30-day abstinence. The final test session lasted 30 min and thus the animals were exposed for $30 \mathrm{~min}$ to alcohol self-administration context. For the last 10 min of the session the animals were exposed to alcohol-related discrete cues (see Figure la). The control animals were always exposed to the same stimuli but were never trained to lever press for any reward and had no access to alcohol. The naive group was occasionally handled and left undisturbed in their home cages. The rats were killed 30 (for P-c-Jun and P-ERKI/2) or 90 min (for c-Fos) after the start of the final session or 30 or 90 min after the handling episode in the case of the naive animals. (a) Analyzed amygdaloid nuclei adapted from Paxinos and Watson (1998). (b) Nuclear localization of c-Fos and P-c-Jun immunostaining within BLA; P-ERKI/2 immunostaining in the neuropil, nuclei and cell bodies of $\mathrm{CeC/L}$. (c) The immunocytochemistry staining with c-Fos antibody performed on 30- $\mu \mathrm{m}$ coronal brain sections and graphic representation of the immunocytochemical data. Note that the extinction/reinstatement session induced c-Fos expression in LaV, BLA, and CeC/L. (d) The immunocytochemistry staining with P-c-Jun antibody performed on 30- $\mu \mathrm{m}$ coronal brain sections and graphic representation of the immunocytochemical data. Note that the extinction/reinstatement session induced P-c-Jun immunostaining within LaV, BLA, BMP, and CeC/L. (e) The immunocytochemistry staining with P-ERKI/2 antibody performed on 30- $\mu \mathrm{m}$ coronal brain sections and graphic representation of the immunocytochemical data. Note that the extinction/reinstatement session induced P-ERKI/2 immunostaining within LaV and BLA. $n=4-6, * p<0.05$, *** $p<0.01$ alcohol vs control, Mann-Whitney U-test with Bonferroni corrections for p-values. LaD, lateral amygdaloid nucleus, dorsal part; LaV, lateral amygdaloid nucleus, ventral part; BLA, basolateral amygdaloid nucleus; BMP, basomedial amygdaloid nucleus, posterior part; CeM, central amygdaloid nucleus, medial division; CeC/L, central amygdaloid nucleus, lateral part and capsular division; MePD, posterodorsal part of the medial amygdaloid nucleus.

c-Jun and regulators of the AP-1 complex activity. In the second experiment, we looked for the possible partners and regulators of c-Fos which could be activated by the alcohol- paired context and discrete cues. For this aim, we analyzed the activation/phosphorylation pattern of c-Jun. ERK1/2 and JNK1/2 have been shown to regulate $c$-fos expression 
and c-Jun phosphorylation, respectively (Sgambato et al, 1998). Given the above, we decided to assess the activation pattern of phosphorylated, ie activated, ERK1/2 and JNK1/2. c-Fos expression was the highest after reexposure to the alcohol-associated context and discrete cues (Table 2). Thus, only the reinstatement groups (Table 1) were tested in the second experiment.

Phospho-c-Jun (P-c-Jun) expression: The activity of cJun protein as a transcription regulator is mainly regulated by its phosphorylated state (Hibi et al, 1993; Gupta et al, 1996; Sgambato et al, 1998; Valjent et al, 2000). Thus, we analyzed the intensity of the phosphorylated form of c-Jun (Ser73). Due to a short half-life of the phosphorylated form of c-Jun, P-c-Jun immunostaining was analyzed in the amygdala immediately after the final test session.

The basal level of P-c-Jun (the naive group) was very low in all the analyzed nuclei of the amygdala (Figure 2d). After the reinstatement session, P-c-Jun immunoreactivity was greater in rats from the alcohol group as compared to the control or naive animals in the $\mathrm{LaV} \quad(p<0.01)$, BLA $(p<0.05)$, BMP $(p<0.05)$, and $\mathrm{CeC} / \mathrm{L} \quad(p<0.05)$ (Figure 2d). P-c-Jun immunostaining showed a specific nuclear localization (Figure $2 \mathrm{~b}$ ).

Phospho-ERK1/2 (P-ERK1/2) expression: To analyze the activation pattern of ERK1/2, we used immunostaining with an antibody detecting phosphorylated forms of ERK1 and ERK2 (Thr183/Tyr185). The P-ERK1/2 immunoreactivity was observed within nuclei of the cells, cell bodies as well as in neuropil (Figure 2e). Since nuclear localization of activated ERK1/2 is believed to be associated with the control of gene expression (Valjent et al, 2000), only immunostained cell nuclei were counted. The alcohol and control animals were killed immediately after the 30-min reinstatement session and the naive animals were anesthetized $30 \mathrm{~min}$ after the brief handling episode. This time point was chosen due to the very short half-life of the phosphorylated forms of ERKs (Valjent et al, 2000).

The basal level of P-ERK1/2 expression, as observed in the naive group, was very low in most of the amygdaloid nuclei except for the CeA (Figure 2e). The reinstatement session induced the increase in P-ERK1/2 immunoreactivity in the alcohol group as compared to the control or naive rats within $\operatorname{LaV}(p<0.01)$ and BLA $(p<0.01)$.

Phospho-JNK (P-JNK) expression: To investigate the activation of JNK1/2, we used immunostaining with antibody detecting phosphorylated forms of JNK1 and JNK2 (Thr183/Tyr185). P-JNK1/2 immunoreactivity was analyzed immediately after the final test session or $30 \mathrm{~min}$ after the short handling in the case of the naive group. The staining was observed in nuclei of the cells, cell bodies, and neuropil (Supplementary Figure 3).

No P-JNK1/2 immunostaining was observed within $\mathrm{LaV}$, $\mathrm{LaD}, \mathrm{BLA}, \mathrm{BMP}$, and MePD in any of the experimental groups (data not shown). Only a few immunostained cells were found within $\mathrm{CeC} / \mathrm{L}, \mathrm{CeM}$, and the piriform cortex (PirCx) (Supplementary Figure 3) but no differences between the experimental groups were observed $(p>0.05$; data not shown).

\section{DISCUSSION}

The results of the present study confirmed the earlier observations that reexposure to drug-paired cues activates c-Fos protein expression in the amygdala. The main new findings of the present study are the following: (1) reexposure to the alcohol-paired context after 30-day abstinence activates the LaV and BLA as revealed by c-Fos immunostaining; (2) reexposure to the alcohol-paired context and discrete cues leads to stronger c-Fos expression in the BLA and $\mathrm{CeC} / \mathrm{L}$ as compared to the presentation of the context stimuli alone; (3) reexposure to the alcoholpaired context and discrete cues activated c-Fos, c-Jun, and the ERK pathway in the LaV and BLA.

\section{Pattern of c-Fos Activation in the Amygdala: A Role in Plasticity}

In the present study, we used immunocytochemical mapping of c-Fos to identify possible loci of plastic changes induced by reexposure to alcohol-paired cues in the withinsession extinction/reinstatement procedure (Bienkowski et al, 2004). The duration of abstinence was chosen on the basis of our previous observation that c-Fos expression in the prefrontal cortex and thalamus induced by reexposure to alcohol-paired cues was significantly higher after 30-day abstinence as compared to 24-h withdrawal (Wedzony et al, 2003). Furthermore, we have shown that alcohol-seeking behavior (lever pressing in extinction) was higher after 30 -day abstinence than after 24 -h or 56-day withdrawal (Bienkowski et al, 2004).

Following 30 days of operant oral alcohol self-administration and 30 days of imposed abstinence, the animals from the alcohol/extinction and alcohol/reinstatement group were reexposed to the Skinner boxes. Reexposure to the alcohol-paired context resulted in vigorous nonreinforced responding on the previously active lever which extinguished during the first $10 \mathrm{~min}$ of the final session. In the previous studies, we have shown that more than $80 \%$ of active lever presses were emitted during the first $10 \mathrm{~min}$ of the extinction/reinstatement session and that there was no recovery of ethanol seeking after the initial burst of responding (Bienkowski et al, 1999, 2000, 2004). In the alcohol/reinstatement group, lever pressing was reinstated by the introduction of discrete alcohol-associated cues. In the previous studies, we have found that 15 non-contingent presentations of the alcohol-associated stimulus complex produced immediate reinstatement of alcohol-seeking behavior (eg Bienkowski et al, 2000). In aggregate, our behavioral observations confirm that both alcohol-paired context and discrete cues may have incentive motivational properties for rats with alcohol self-administration history (McBride and Li, 1998; Le and Shaham, 2002; McBride et al, 2002).

The immunocytochemical analysis indicated that reexposure to alcohol-paired discrete cues potently activated c-Fos expression in the $\mathrm{BLA}$ and CeC/L. Importantly, c-Fos expression within these nuclei did not correlate with alcohol-seeking behavior, ie the number of non-reinforced lever presses for alcohol. The latter finding suggests that c-Fos expression was activated by the presentation of alcohol-paired stimuli and not by the performance of 
operant behavior. Our observation of increased c-Fos expression in the BLA after reexposure to the alcoholpaired discrete cues is in agreement with earlier studies which showed that reexposure to cocaine-, amphetamine-, morphine-, or beer-associated context and discrete cues activated c-Fos in this brain region (Topple et al, 1998; Baker et al, 1999; Mead et al, 1999; Neisewander et al, 2000; Ciccocioppo et al, 2001; Harris and Aston-Jones, 2003). Moreover, the BLA has been shown to be involved in context- and cue-induced relapse to drug-seeking, and to control the ability of environmental stimuli to form Pavlovian associations with reinforcing stimuli (Whitelaw et al, 1996; Meil and See, 1997; Kruzich and See, 2001; Shalev et al, 2003). Taken together, these studies may indicate that activation of c-Fos expression in the BLA observed in the present study is related to the general role which this amygdaloid nucleus plays in the formation of current stimulus-value associations (Cardinal et al, 2002; see Knapska et al, 2007 for extensive review).

The role of the CeA in cue-induced relapse seems to be more controversial. It has been shown that cocaine- and alcohol-paired discrete cues did not activate c-Fos expression in the CeA (Neisewander et al, 2000; Ciccocioppo et al, 2001; Dayas et al, 2007; Zhao et al, 2006). However, in the latter studies many extinction sessions were run prior to the final reinstatement session (a factor which could account for the discrepancies between the results of those studies and our data). On the other hand, exposure to amphetamine or morphine-paired context in the conditioned place preference paradigm (Mead et al, 1999; Harris and AstonJones, 2003) or presentation of heroin-paired cues (Koya et al, 2006) activated the CeA as far as c-Fos expression is concerned. Inhibition of the ERK pathway in the CeA decreased cocaine seeking after 30 days of abstinence (Lu et al, 2005). Given the above, our data may suggest the $\mathrm{CeC} / \mathrm{L}$ is a neural substrate of experimental alcohol craving induced by discrete cues.

The $\mathrm{CeC} / \mathrm{L}$ was hypothesized to be involved in the attentional processes (Holland and Gallagher, 1993). Thus, increased $\mathrm{c}$-Fos expression in the $\mathrm{CeC} / \mathrm{L}$ may be related to the well-known effect of drug-paired cues on addicts' attention and physiological state (Franken, 2003). It is also worthy to note that dopaminergic fibers are more numerous in the BLA and CeA as compared to the MePD and BMP (Asan, 1998). This could make the former nuclei more sensitive to dopamine released upon stimulation with drug- and alcohol-related context or discrete stimuli (Tran-Nguyen et al, 1998).

Interestingly, c-Fos expression observed in the amygdala following reexposure to the alcohol-paired cues does not fully resemble the pattern of c-Fos activation after passive alcohol injections. In the latter case, the activation of the CeA was repeatedly observed (Chang et al, 1995; Ryabinin et al, 1997; Ryabinin and Wang, 1998) while the activation of the BLA was less clear (Bachtell et al, 1999; Ryabinin et al, 2000).

Importantly, our study raises the question as to whether the observed pattern of molecular alterations is specific to addictive reinforcers or could be generalized to natural rewards. In our previous paper, we have reported that reexposure to sucrose self-administration environment did not induce c-Fos expression in the amygdala (Wedzony et al, 2003). Our observation is in agreement with the finding of Koya et al (2006), who have shown no increase in $c$-fos mRNA in the BLA following presentation of sucrosepaired cues. On the other hand, Hamlin et al (2006) have found that exposure to sucrose self-administration context activated c-Fos in the BLA, and Lee et al (2005) have reported that presentation of visual stimuli paired with food may induce c-Fos expression in the CeA. This ambiguous pattern of c-Fos expression found by different researchers could be interpreted in the way that natural rewardassociated cues may induce c-Fos in the BLA and CeA but to a lesser extent then drug-associated cues. Accordingly, the level of c-Fos expression induced in the amygdala by reward-associated cues could indicate the addictive properties of primary reward. On the other hand, exposure to context cues associated with electric shock consistently induced c-Fos expression both in the BLA and CeA (Beck and Fibiger, 1995; Holahan and White, 2004; Scicli et al, 2004). Thus, the most important factor which affects the pattern of c-Fos expression in the amygdala may be the motivational value of unconditioned stimulus but not its addictive properties.

Although c-Fos expression has been extensively studied in many models related to drug addiction, there are not many studies which describe concomitant activation of $\mathrm{c}$ Fos partners in the AP-1 complex. In the present study, we showed for the first time that c-Jun protein can be activated concomitantly with c-Fos in some amygdaloid nuclei after reexposure to the alcohol-paired context and discrete cues. This observation may indicate that relapse to alcohol seeking leads to formation of the AP-1 transcription factor and regulation of some AP-1-dependent genes. Our findings may also suggest that the expression of c-Fos and activation of c-Jun may be co-regulated in the $\mathrm{LaV}, \mathrm{BLA}$, and CeC/L. Since the AP-1 transcription factor, with Fos and Jun components, is a known marker of neuronal plasticity (Kaczmarek and Chaudhuri, 1997; Rylski and Kaczmarek, 2004), it is tempting to speculate that the LaV, BLA, and $\mathrm{CeC} / \mathrm{L}$ are the loci of plastic changes associated with perception of discrete alcohol-related cues, and that the activation of AP-1 in these nuclei could be a critical molecular event in the adaptive responses to drug-related stimuli.

\section{Regulation of c-Fos Expression and c-Jun Activation Induced by Alcohol-Paired Cues}

It is known that c-Fos protein expression in the amygdala induced by cocaine-predictive cues depends on stimulation of dopamine D1 receptors (Ciccocioppo et al, 2001). It can also be speculated that c-Fos expression induced by drugrelated cues is driven by ERK-dependent phosphorylation of Elk-1 and CREB transcription factors (Sgambato et al, 1998; Vanhoutte et al, 1999; Valjent et al, 2000). c-Fos protein expression and the ERK pathway have been shown to be activated in the amygdala after reexposure to drugpaired stimuli (Neisewander et al, 2000; Lu et al, 2005), what may suggest the involvement of ERK pathway in the regulation of c-Fos expression. However, there is also evidence that cocaine-induced c-Fos expression in the 
amygdala may not depend on the ERK pathway (Radwanska et al, 2005). Other elements of the molecular cascade activated by drug-paired cues remain unknown. In the present study, c-Fos activation in the LaV and BLA after reexposure to the alcohol-associated stimuli followed the expression of the activated form of ERKs (P-ERK1/2) in the same nuclei. This finding suggests that, in the animal model of relapse to alcohol seeking, c-Fos expression in the $\mathrm{LaV}$ and BLA might be driven by the ERK pathway. Interestingly, in the CeA, we observed c-Fos activation after the extinction/reinstatement session, but no increase in the level of P-ERK1/2. The observed discrepancy probably arose due to a very high basal level of P-ERK1/2 in the CeA. This situation does not exclude the possibility that c-Fos expression in the CeA may also be driven by the ERK pathway.

Our findings strengthen the earlier notions that the ERK pathway is involved in the molecular basis of drug and alcohol addiction (Valjent et al, 2004; Girault et al, 2007). The inhibition of ERKs in the amygdala has been reported to block the formation of long-term fear memory (Schafe et al, 2000), memory reconsolidation (Duvarci et al, 2005), and extinction (Herry et al, 2006). Furthermore, Valjent et al (2006) have shown that inhibition of the ERK pathway prior to reexposure to cocaine-paired context blocked conditioned place preference on the following trial. Future studies will show whether inhibition of ERKs in the amygdala could also interfere with cue-induced alcohol seeking.

Interestingly, although P-c-Jun expression was observed in the amygdala after reexposure to the alcohol-paired stimuli, P-JNK, the main activator of c-Jun (Hibi et al, 1993; Gupta et al, 1996) was not expressed in the amygdaloid nuclei. On the other hand, P-c-Jun was co-expressed with PERK in the LaV and BLA of the alcohol rats reexposed to the alcohol-paired stimuli. Hence, one may hypothesize that in our model of cue-induced alcohol seeking it is rather the ERK pathway which is responsible for c-Jun activation in the amygdala. The above hypothesis needs further validation in future studies.

In conclusion, our results showed that the discrete alcohol-paired cues activated specifically c-Fos expression in the BLA and CeC/L. Furthermore, c-Fos expression in the BLA was associated with increased c-Jun and ERK phosphorylation. These findings may indicate that the BLA (and possibly the CeC/L) is specifically involved in alcohol-seeking behavior induced by discrete cues.

\section{ACKNOWLEDGEMENTS}

The study was supported by The State Committee for Scientific Research (grant no. PBZ-KBN-033/P05/2000) and by the Polish Ministry of Science and Higher Education Scientific Network Fund.

\section{DISCLOSURE/CONFLICT OF INTEREST}

The authors declare that there is no conflict of interest. KR, $\mathrm{EW}, \mathrm{AK}, \mathrm{AR}, \mathrm{WK}$, and LK declare that except from the income received from the primary employer, no financial support or compensation has been received from any individual or corporate entity over the past 3 years for research or professional service and there are no personal financial holdings that could be perceived as constituting a potential conflict of interest. $\mathrm{PB}$ received fees for professional consultation and lectures from Adamed, Bayer, NeuroSearch, Orphan Pharmaceuticals, Polfa Tarchomin, and Sanofi-Aventis.

\section{REFERENCES}

Asan E (1998). The catecholaminergic innervation of the rat amygdala. Adv Anat Embryol Cell Biol 142: 1-118.

Bachtell RK, Wang YM, Freeman P, Risinger FO, Ryabinin AE (1999). Alcohol drinking produces brain region-selective changes in expression of inducible transcription factors. Brain Res 847: 157-165.

Baker DA, Fuchs RA, Tran-Nguyen LT, Palmer AJ, Marshall JF, McPherson RJ et al (1999). Cocaine-seeking behavior and Fos expression in the amygdala produced by cocaine or a cocaine self-administration environment. Ann NY Acad Sci 877: 796-799.

Beck CH, Fibiger HC (1995). Conditioned fear-induced changes in behavior and in the expression of the immediate early gene c-fos: with and without diazepam pretreatment. J Neurosci 15: 709-720.

Berke JD, Hyman SE (2000). Addiction, dopamine, and the molecular mechanisms of memory. Neuron 25: 515-532.

Bienkowski P, Koros E, Kostowski W, Bogucka-Bonikowska A (2000). Reinstatement of ethanol seeking in rats: behavioral analysis. Pharmacol Biochem Behav 66: 123-128.

Bienkowski P, Kostowski W, Koros E (1999). The role of drugpaired stimuli in extinction and reinstatement of ethanolseeking behaviour in the rat. Eur J Pharmacol 374: 315-319.

Bienkowski P, Rogowski A, Korkosz A, Mierzejewski P, Radwanska $\mathrm{K}$, Kaczmarek L et al (2004). Time-dependent changes in alcohol-seeking behaviour during abstinence. Eur Neuropsychopharmacol 14: 355-360.

Brown EE, Robertson GS, Fibiger HC (1992). Evidence for conditional neuronal activation following exposure to a cocaine-paired environment: role of forebrain limbic structures. J Neurosci 12: 4112-4121.

Cardinal RN, Parkinson JA, Hall J, Everitt BJ (2002). Emotion and motivation: the role of the amygdala, ventral striatum, and prefrontal cortex. Neurosci Biobehav Rev 26: 321-352.

Chang SL, Patel NA, Romero AA (1995). Activation and desensitization of Fos immunoreactivity in the rat brain following ethanol administration. Brain Res 679: 89-98.

Ciccocioppo R, Sanna PP, Weiss F (2001). Cocaine-predictive stimulus induces drug-seeking behavior and neural activation in limbic brain regions after multiple months of abstinence: reversal by $\mathrm{D}(1)$ antagonists. Proc Natl Acad Sci USA 98: 1976-1981.

Dayas CV, Liu X, Simms JA, Weiss F (2007). Distinct patterns of neural activation associated with ethanol seeking: effects of naltrexone. Biol Psychiatry 15: 979-989.

Drummond DC, Cooper T, Glautier SP (1990). Conditioned learning in alcohol dependence: implications for cue exposure treatment. Br J Addict 85: 725-743.

Duvarci S, Nader K, LeDoux JE (2005). Activation of extracellular signal-regulated kinase- mitogen-activated protein kinase cascade in the amygdala is required for memory reconsolidation of auditory fear conditioning. Eur J Neurosci 21: 283-289.

Franken IH (2003). Drug craving and addiction: integrating psychological and neuropsychopharmacological approaches. Prog Neuropsychopharmacol Biol Psychiatry 27: 563-579.

George MS, Anton RF, Bloomer C, Teneback C, Drobes DJ, Lorberbaum JP et al (2001). Activation of prefrontal cortex and 
anterior thalamus in alcoholic subjects on exposure to alcoholspecific cues. Arch Gen Psychiatry 58: 345-352.

Girault JA, Valjent E, Caboche J, Herve D (2007). ERK2: a logical AND gate critical for drug-induced plasticity? Curr Opin Pharmacol 7: 77-85.

Grimm JW, See RE (2000). Dissociation of primary and secondary reward-relevant limbic nuclei in an animal model of relapse. Neuropsychopharmacology 22: 473-479.

Gupta S, Barrett T, Whitmarsh AJ, Cavanagh J, Sluss HK, Derijard B et al (1996). Selective interaction of JNK protein kinase isoforms with transcription factors. EMBO J 15: 2760-2770.

Hamlin AS, Blatchford KE, McNally GP (2006). Renewal of an extinguished instrumental response: neural correlates and the role of D1 dopamine receptors. Neuroscience 143: 25-38.

Harris GC, Aston-Jones G (2003). Enhanced morphine preference following prolonged abstinence: association with increased Fos expression in the extended amygdala. Neuropsychopharmacology 28: 292-299.

Herdegen T, Leah JD (1998). Inducible and constitutive transcription factors in the mammalian nervous system: control of gene expression by Jun, Fos and Krox, and CREB/ATF proteins. Brain Res Rev 28: 370-490.

Herry C, Trifilieff P, Micheau J, Luthi A, Mons N (2006). Extinction of auditory fear conditioning requires MAPK/ERK activation in the basolateral amygdala. Eur J Neurosci 24: 261-269.

Hibi M, Lin A, Smeal T, Minden A, Karin M (1993). Identification of an oncoprotein- and UV-responsive protein kinase that binds and potentiates the c-Jun activation domain. Genes Dev 7: 2135-2148.

Holahan MR, White NM (2004). Amygdala c-Fos induction corresponds to unconditioned and conditioned aversive stimuli but not to freezing. Behav Brain Res 152: 109-120.

Holland PC, Gallagher M (1993). Effects of amygdala central nucleus lesions on blocking and unblocking. Behav Neurosci 107: 235-245.

Impey S, Obrietan K, Storm DR (1999). Making new connections: role of ERK/MAP kinase signaling in neuronal plasticity. Neuron 23: $11-14$

Kaczmarek L (1993). Molecular biology of vertebrate learning: is c-fos a new beginning? J Neurosci Res 34: 377-381.

Kaczmarek L, Chaudhuri A (1997). Sensory regulation of immediate-early gene expression in mammalian visual cortex: implications for functional mapping and neural plasticity. Brain Res Brain Res Rev 23: 237-256.

Knapska E, Radwanska K, Werka T, Kaczmarek L (2007). Functional internal complexity of amygdala: focus on gene activity mapping following behavioural training and drugs of abuse. Phys Rev (in press).

Koya E, Spijker S, Voorn P, Binnekade R, Schmidt ED, Schoffelmeer AN et al (2006). Enhanced cortical and accumbal molecular reactivity associated with conditioned heroin, but not sucrose-seeking behaviour. I Neurochem 98: 905-915.

Kruzich PJ, See RE (2001). Differential contributions of the basolateral and central amygdala in the acquisition and expression of conditioned relapse to cocaine-seeking behavior. I Neurosci 21: RC155.

Le A, Shaham Y (2002). Neurobiology of relapse to alcohol in rats. Pharmacol Ther 94: 137-156.

Lee HJ, Groshek F, Petrovich GD, Cantalini JP, Gallagher M, Holland PC (2005). Role of amygdalo-nigral circuitry in conditioning of a visual stimulus paired with food. J Neurosci 25: 3881-3888.

Lu L, Hope BT, Dempsey J, Liu SY, Bossert JM, Shaham Y (2005). Central amygdala ERK signaling pathway is critical to incubation of cocaine craving. Nat Neurosci 8: 212-219.

McBride WJ, Le AD, Noronha A (2002). Central nervous system mechanisms in alcohol relapse. Alcohol Clin Exp Res 26: $280-286$
McBride WJ, Li TK (1998). Animal models of alcoholism: neurobiology of high alcohol-drinking behavior in rodents. Crit Rev Neurobiol 12: 339-369.

Mead AN, Vasilaki A, Spyraki C, Duka T, Stephens DN (1999). AMPA-receptor involvement in c-fos expression in the medial prefrontal cortex and amygdala dissociates neural substrates of conditioned activity and conditioned reward. Eur J Neurosci 11: 4089-4098.

Meil WM, See RE (1997). Lesions of the basolateral amygdala abolish the ability of drug associated cues to reinstate responding during withdrawal from self-administered cocaine. Behav Brain Res 87: 139-148.

Neisewander JL, Baker DA, Fuchs RA, Tran-Nguyen LT, Palmer A, Marshall JF (2000). Fos protein expression and cocaine-seeking behavior in rats after exposure to a cocaine self-administration environment. J Neurosci 20: 798-805.

Paxinos G, Watson C (1998). The Rat Brain in Stereotaxic Coordinates. Academic Press: New York.

Quinn GP, Keough MJ (2002). Experimental Design and Data Analysis for Biologists. Cambridge University Press: Cambridge.

Radwanska K, Caboche J, Kaczmarek L (2005). Extracellular signal-regulated kinases (ERKs) modulate cocaine-induced gene expression in the mouse amygdala. Eur J Neurosci 22: 939-948.

Ryabinin AE, Criado JR, Henriksen SJ, Bloom FE, Wilson MC (1997). Differential sensitivity of c-Fos expression in hippocampus and other brain regions to moderate and low doses of alcohol. Mol Psychiatry 2: 32-43.

Ryabinin AE, Wang YM (1998). Repeated alcohol administration differentially affects c-Fos and FosB protein immunoreactivity in DBA/2J mice. Alcohol Clin Exp Res 22: 1646-1654.

Ryabinin AE, Wang YM, Bachtell RK, Kinney AE, Grubb MC, Mark GP (2000). Cocaine- and alcohol-mediated expression of inducible transcription factors is blocked by pentobarbital anesthesia. Brain Res 877: 251-261.

Rylski M, Kaczmarek L (2004). AP-1 targets in the brain. Front Biosci 9: 8-23.

Samson HH (1986). Initiation of ethanol reinforcement using a sucrose-substitution procedure in food- and water-sated rats. Alcohol Clin Exp Res 10: 436-442.

Samson HH, Czachowski CL, Slawecki CJ (2000). A new assessment of the ability of oral ethanol to function as a reinforcing stimulus. Alcohol Clin Exp Res 24: 766-773.

Schafe GE, Atkins CM, Swank MW, Bauer EP, Sweatt JD, LeDoux JE (2000). Activation of ERK/MAP kinase in the amygdala is required for memory consolidation of pavlovian fear conditioning. J Neurosci 20: 8177-8187.

Scicli AP, Petrovich GD, Swanson LW, Thompson RF (2004). Contextual fear conditioning is associated with lateralized expression of the immediate early gene c-fos in the central and basolateral amygdalar nuclei. Behav Neurosci 118: 5-14.

Sgambato V, Pages C, Rogard M, Besson MJ, Caboche J (1998). Extracellular signal-regulated kinase (ERK) controls immediate early gene induction on corticostriatal stimulation. J Neurosci 18: 8814-8825.

Shaham Y, Erb S, Stewart J (2000). Stress-induced relapse to heroin and cocaine seeking in rats: a review. Brain Res Rev 33: 13-33.

Shaham Y, Shalev U, Lu L, De Wit H, Stewart J (2003). The reinstatement model of drug relapse: history, methodology and major findings. Psychopharmacology (Berl) 168: 3-20.

Shalev U, Grimm JW, Shaham Y (2002). Neurobiology of relapse to heroin and cocaine seeking: a review. Pharmacol Rev 54: 1-42.

Shalev U, Roberts P, Shaham Y, Morales M (2003). Selective induction of c-Fos immunoreactivity in the prelimbic cortex during reinstatement of heroin seeking induced by acute food deprivation in rats. Behav Brain Res 145: 79-88.

Topple AN, Hunt GE, McGregor IS (1998). Possible neural substrates of beer-craving in rats. Neurosci Lett 252: 99-102. 
Tran-Nguyen LT, Fuchs RA, Coffey GP, Baker DA, O’Dell LE, Neisewander JL (1998). Time-dependent changes in cocaineseeking behavior and extracellular dopamine levels in the amygdala during cocaine withdrawal. Neuropsychopharmacology 19: $48-59$.

Valjent E, Corbille AG, Bertran-Gonzalez J, Herve D, Girault JA (2006). Inhibition of ERK pathway or protein synthesis during reexposure to drugs of abuse erases previously learned place preference. Proc Natl Acad Sci USA 103: 2932-2937.

Valjent E, Corvol JC, Pages C, Besson MJ, Maldonado R, Caboche J (2000). Involvement of the extracellular signal-regulated kinase cascade for cocaine-rewarding properties. J Neurosci 20: 8701-8709.

Valjent E, Pages C, Herve D, Girault JA, Caboche J (2004). Addictive and non-addictive drugs induce distinct and specific patterns of ERK activation in mouse brain. Eur J Neurosci 19: 1826-1836.

Vanhoutte P, Barnier JV, Guibert B, Pages C, Besson MJ, Hipskind RA et al (1999). Glutamate induces phosphorylation of Elk-1 and CREB, along with c-fos activation, via an extracellular signal- regulated kinase-dependent pathway in brain slices. Mol Cell Biol 19: 136-146.

Wedzony K, Koros E, Czyrak A, Chocyk A, Czepiel K, Fijal K et al (2003). Different pattern of brain c-Fos expression following reexposure to ethanol or sucrose self-administration environment. Naunyn Schmiedebergs Arch Pharmacol 368: 331-341.

Whitelaw RB, Markou A, Robbins TW, Everitt BJ (1996). Excitotoxic lesions of the basolateral amygdala impair the acquisition of cocaine-seeking behaviour under a secondorder schedule of reinforcement. Psychopharmacology (Berl) 127: 213-224.

Yun IA, Fields HL (2003). Basolateral amygdala lesions impair both cue- and cocaine-induced reinstatement in animals trained on a discriminative stimulus task. Neuroscience 121: 747-757.

Zhao Y, Dayas CV, Aujla H, Baptista MA, Martin-Fardon R, Weiss F (2006). Activation of group II metabotropic glutamate receptors attenuates both stress and cue-induced ethanolseeking and modulates $c$-fos expression in the hippocampus and amygdala. J Neurosci 26: 9967-9974.

Supplementary Information accompanies the paper on the Neuropsychopharmacology website (http://www.nature.com/npp) 